\title{
PEMBELAJARAN NILAI AL ISLAM KEMUHAMMADIYAHAN DI TK ABA PANTO DAENG SUMBAWA BESAR DAN TK ABA TALIWANG SUMBAWA BARAT
}

Mardiyah Hayati 1, Aqodiah 2

1,2Program Studi PGMI, Universitas Muhammadiyah Mataram, Indonesia Mardiyahhayai4@gmail.com ${ }^{1}$, aqodiiah@gmail.com ${ }^{2}$

\section{INFO ARTIKEL}

\section{Riwayat Artikel:}

Diterima: 02-09-2019

Disetujui: 30-10-2019

\section{Kata Kunci:}

Materi Al Islam

Kemuhammadiyahan;

Strategi dalam

pembelajaran AIK;

masa keemasan

perkembangan seorang

anak.

\section{Keywords:}

The material of

Kemuhammadiyahan;

The strategy in AIK

learning;

The golden age of a child's development.

\section{A. LATAR BELAKANG}

Agama Islam sangat memperhatikan anakanak dan pemuda. Mereka adalah anggota keluarga yang berhak mendapatkan lebih banyak pendidikan dan pembelajaran untuk menjadi generasi yang mengenal agamanya dan beradab. Selain itu mereka adalah generasi masa depan, harapan ummat dan harapan bangsa. Untuk

\section{ABSTRAK}

Abstrak: Tujuan penelitian ini adalah untuk mengetahui bagaimana nilai-nilai pembelajaran, materi, strategi dan model pembelajarannya Al Islam dan Kemuhammadiyahan di TK ABA Panto Daeng Sumbawa Besar dan TK ABA Taliwang Sumbawa Barat. Penelitian ini merupakan penelitian lapangan (field research), dan jenis pendekatan yang digunakan adalah bersifat kualitatif dengan metode wawancara, observasi, dan dokumentasi. Beberapa kesimpulan dari hasil penelitian dilapangan; Pertama, perlu adanya pendalaman pada penulisan sejarah Muhammadiyah dan 'Aisyiyah di Sumbawa Besar dan Sumbawa Barat. Kedua, dalam pembelajaran Al Islam dan Kemuhammadiyahan di TK 'Aisyiyah Panto Daeng Sumbawa Besar dan TK Aisyiyah Taliwang Sumbawa Barat ditemukan adanya kesamaan pola pembelajaran. Kesamaan ini dipengaruhi oleh persamaan penguasaan guru terhadap materi Al Islam dan Kemuhammadiyahan. Ketiga, masih minimnya strategi pembelajaran yang menarik dalam penanaman nilai-nilai Al Islam dan Kemuhammadiyahan sehingga perlu adanya pola dan model strategi pembelajaran AIK bagi anak usia Taman Kanak-kanak. Keempat, perlu adanya pelatihan bagi guru terkait pemahaman mendalam terhadap konsep ibadah berdasarkan manhaj Muhammadiyah sehingga dalam pembelajaran AIK acuan utamanya adalah Himpunan Putusan Tarjih Muhammadiyah.

Abstract: The purpose of this research is to know how the values of learning, materials, strategies and models of teaching Al Islam and Kemuhammadiyahan in TK ABA Panto Daeng Sumbawa Besar and TK ABA Taliwang West Sumbawa. This research is a field research, and the type of approach used is qualitative with methods of interviews, observations, and documentation. Some conclusions of the research in field; First, there has to be a deepening of the history of Muhammadiyah and Aisyiyah in Sumbawa Besar and West Sumbawa. Secondly, in the study of Al Islam and Kemuhammadiyahan in TK Aisyiyah Panto Daeng Sumbawa Besar and TK Aisyiyah Taliwang Sumbawa Barat found a common pattern of learning. This similarity is influenced by the teacher's mastery equality to the Al Islam material and the Kemuhammadiyahan. Thirdly, there is still a lack of interesting learning strategy in the planting values of Al Islam and Kemuhammadiyahan so there needs to be a pattern and model of AIK learning strategy for children of kindergarten. Fourth, there needs to be training for teachers regarding the deep understanding of the concept of worship based on Muhammadiyah Manhaj so that in the study of AIK main reference is the association of the decision Tarjih Muhammadiyah. 
Muhammadiyah memiliki 6723 PAUD (Pendidikan Anak Usia Dini), 7.623 TK ABA Bustanul Athfal,2604 SD/MI (Sekolah Dasar /Madrasah Ibtidaiyah), 1772 SMP/MTs (Sekolah Madrasah Pertama/ Madrasah Tsanawiyah), 1143 SMA/SMK/MA (Sekolah Menengah Atas/Sekolah Menenengah Kejuruan/Madrasah Aliyah), 183 PT (Perguruan Tinggi), 82 Pondok Pesantren dan 71 SLB (Sekolah Luar Biasa).

Sementara khusus amal usaha 'Aisyiyah dalam bidang pendidikan terdiri dari 1385 Kelompok Bermain,1607 Satuan PAUD sejenis,5717 TK,8816 PAUD,72 Taman Pengasuhan Anak,1579 Taman Pendidikan Al Qur'an,18 SD,5 MI,4 SMP,8 MTs,5 SMK,3 SMU,229 Madrasah Diniyah Awaliyah Putri,3 Pesantren,18 SLB dan 9 Perguruan Tinggi 'Aisyiyah (PTA). Aisyiyah juga memiliki pendidikan non formal yang terdiri dari 3904 Keaksaraanfungsional,3 Taman Baca Masyarakat,7 Pusat Kegiatan Masyarakat,171 Lifeskill.

Sebagai amal usaha Muhammadiyah dan 'Aisyiyah dalam pembelajaran Pendidikan Agama Islam tentu memiliki identitas yang membedakannya dengan lembaga pendidikan lainnya. Identitas yang membuatnya berbeda dan memiliki ciri-ciri khusus yang melekat sehingga memiliki daya beda dengan yang lain.

Perbedaan karakter pendidikan Muhammadiyah di tuliskan oleh Mohammad Ali dan Marpuji Ali menjadi lima ciri khas : 1).Menumbuhkan cara berpikir pembaharuan (tajdid), 2) kepemimpinan pluralistic, 3) berwatak mandiri, 4) kemampuan berpikir antisipatif dan 5) menggunakan strategi moderasi,bukan radikal dalam menyikapi dan menghadapi suatu permasalahan.

Dalam penyelenggaraan pendidikan, Muhammadiyah memutuskan pada Muktamar ke 44 di Jakarta tahun 2000 dua programnya yaitu : 1) memasukkan fungsi kaderisasi (pengkaderan) dalam perencanaan strategis dan penyelenggaraan seluruh jenjang untuk menghasilkan lulusan yang sesuai dengan tujuan pendidikan Muhammadiyah, yaitu manusia muslim yang berakhlak mulia,cerdas dan berguna bagi ummat dan bangsa. 2) Khusus untuk Taman Kanak-kanak Busthanul Athfal, Play group dan Taman pendidikan Al Qur'an, pendidkan formal dan non formal hendaknya dijadikan sebagai wahana persemaian. Oleh karena itu identitas/kekhasan dalam lembaga pendidikan Muhammadiyah dan 'Aisyiyah adalah adanya mata pelajaraan Al Islam dan Kemuhammadiyahan

Pimpinan Daerah 'Aisyiyah (PDA) Sumbawa Besar hingga saat ini memiliki 13 Taman KanakKanak Bustanul Athfal yang tersebar di beberapa
Pimpinan Cabang 'Aisyiyah demikian juga dengan Pimpinan Daerah 'Aisyiyah (PDA) Sumbawa Barat memiliki 1 TK 'Aisyiyah Bustanul Athfal. Peneliti tertarik untuk meneliti dan mendiskripsikan tentang materi dan strategi pembelajaran Al Islam Kemuhammadiyahan di TK ABA di Sumbawa Besar khususnya di TK ABA Panto Daeng sebagai TK ABA pertama yang dirikan oleh Pimpinan Daerah 'Aisyiyah Sumbawa Besar dan TK ABA Taliwang Sumbawa Barat, dengan harapan dapat menjadi model pembelajaran Al Islam Kemuhammadiyahan di seluruh TK ABA di Nusa Tenggara Barat yang sesuai dengan perkembangan anak-anak.

\section{B. METODE PENELITIAN}

Penelitian ini dilakukan di TK 'Aisyiyah Bustanul Athfal Panto Daeng Sumbawa Besar dan TK 'Aisyiyah Taliwang Sumbawa Barat Tahun ajaran 2018-2019. Subyek atau responden dalam penelitian ini adalah kepala sekolah, guru dan beberapa murid TK 'ABA Panto Daeng Sumbawa Besar dan TK ABA Taliwang Sumbawa Barat. Demikian juga sesepuh 'Aisyiyah di Kota Sumbawa Besar dan Sumbawa Barat yang telah berjasa dalam mendirikan sekolah juga menjadi subyek responden peneliti.

Jumlah guru di TK ABA Panto Daeng Sumbawa Besar pada tahun akademik 2018-2019 adalah 7 orang,sementara jumlah siswa secara keseluruhan adalah 68 oarng terdiri dari 3 kelas : kelas A1 berjumlah 21 orang, kelas B1 berjumlah 30 orang dan kelas B 2 jumlah siswa adalah 17 orang. Sementara jumlah guru di TK ABA Taliwang Sumbawa Barat berjumlah 7 orang. Dengan jumlah siswa sebanyak 78 orang terdiri dari kelas A berjumlah 34 siswa dan kelas B berjumlah 44 orang.

Metode pengumpulan data yang di gunakan dalam penelitian ini adalah : observasi, wawancara dan dokumentasi.

1. Metode observasi atau pengamatan di lakukan pada waktu tindakan sedang berlangsung. Observasi pertama kali dilakukan secara menyeluruh terhadap phenomena yang akan diteliti dengan melakukan penelitian melalui kajian pustaka dan fenomena lapangan yang akan di teliti guna memperoleh fokus penelitian dan mempelajari masalah penelitian. Dengan demikian obsevasi adalah pengamatan atau penyelidikan yang digunakan dengan menggunakan alat indera,baik langsung maupun tidak langsung terhadap fakta-fakta atau gejala-gejala yang akan diteliti. Tehnik obsevasi digunakan untuk membuktikan kebenaran data atau informasi yang diperoleh 
melalui wawancara. Dalam observasi akan diamati adalah materi, strategi, yang tertulis dalam silabus pembelajaran Al Islam dan Kemuhammadiyahan. Peneliti akan mengamati secara langsung dan natural tanpa rekayasa yang terjadi selama observasi berlangsung. Untuk memperoleh data yang cermat peneliti akan berupaya untuk memasuki kondisi obyek. Sebelum memulai observasi peneliti, menyiapkan segala bentuk perlengkapan seperti kamera dan tape recorder. Observasi dilakukan baik secara langsung maupun tidak langsung. Dalam hal ini observasi dilakukan di TK ABA Panto Daeng Sumbawa Besar dan TK ABA Taliwang Sumbawa Barat pada bulan April 2019.

2. Metode wawancara. Adalah pertemuan antara dua orang,melibatkan seseorang yang ingin memperoleh informasi dari sesorang lainnya dengan mengajukan pertanyaan-pertanyaan berdasarkan tujuan tertentu. Wawancara yang digunakan dalam menjaring informasi dalam penelitian ini adalah guru,kepala sekolah dan sesepuh organisasi 'Aisyiyah di Kabupaten Sumbawa dan Sumbawa Barat yang berjasa dalam membangun dan mendirikan TK ABA dalam hal ini adalah TK ABA Panto Daeng dan TK ABA Taliwang. Adapun teknik wawancara yang digunakan dalam penelitian ini wawancara terstruktur dan tidak terstruktur agar lebih luwes,dimana susunan pertanyaan dan katakata dalam setiap pertanyaan dapat diubah saat wawancara,disesuaikan dengan kebutuhan dan kondisi saat wawancara dilakukan. Pengumpulan data dengan tehnik ini bertujuan untuk memperoleh informasi dan keterangan baik itu dari subyek maupun informan yang berkaitan dengan materi,strategi dan model pembelajaran di TK ABA Panto Daeng dan TK ABA Taliwang Sumbawa Barat.

3. Metode dokumentasi adalah pengambilan data yang di peroleh melalui dokumen-dokumen. Dokumen yang artinya barang-barang tertulis. Dalam melaksanakan metode dokumentasi, peneliti menyelidiki benda-benda tertulis seperti buku notulen rapat,catatan harian,arsip dan lain sebagainya. Dari definisi tersebut diketahui bahwa tehnik dokumentasi adalah suatu tehnik penelitian yang ditujukan kepada penguraian dan penjelasan terhadap apa yang tengah berlangsung melalui sumber-sumber dokumen dalam menggali suatu data. Dalam hal ini adalah dokumentasi tentang materi,strategi dan model pembelajaran di TK ABA Panto Daeng dan TK ABA Taliwang Sumbawa Barat.
Beberapa langkah yang dapat dilakukan dalam menganalisis data antara lain : Pertama adalah mereduksi data. Reduksi dilakukan dengan mengumpulkan data dari hasil wawancara, obsevasi dan dokumentasi serta data lapangan,kemudian dipilih dan dikelompokkan berdasarkan kemiripan data. Hasilnya kemudian akan diolah,diklasfikasi,dianalisis dan disimpulkan.

Langkah kedua yaitu penyajian data. Dalam hal ini data yang telah dikatagorikan tersebut kemudian diorganisasikan sebagai bahan penyajian data. Data tersebut disajikan secara deskriptif yang didasarkan pada aspek yang diteliti sehingga dimungkinkan dapat memberikan gambaran seluruhnya atau sebagian dari aspek yang akan diteliti.

Langkah ketiga verifikasi dan menyimpulkan,dalam hal ini peneliti akan menyeleksi kembali, mengklasifikasi dan menganalisi data kemudian menyimpulkan kembali. Tehnik pengambilan kesimpulan yang dipakai adalah metode deduksi dan induksi.Setelah itu data dianggap selesai dan dijadikan sebagai data akhir yang dijadikan sebagai bahan laporan penelitian.

\section{HASIL DAN PEMBAHASAN}

Pada tahun 1990 seorang tokoh 'Aisyiyah yaitu Ibu Hanna Hamid di Sumbawa Besar mewakafkan tanah kepada PDA Sumbawa dengan niat untuk dimanfaatkan oleh 'Aisyiyah di bidang pendidikan. Lokasi tanah wakaf tersebut berada di Jalan Baru. Lokasinya cukup jauh dari kota kabupaten. Tanah wakaf tersebut berjumlah 400 $\mathrm{m} 2$. Selama beberapa tahun tanah tersebut belum dimanfaatkan oleh PDA Sumbawa hingga suatu saat pada masa kepemimpinan ibu Hj Sri Sayekti Sugimin, tanah yang semula berada di Jalan Baru ditukar guling ke lokasi tanah di daerah sekitar Panto Daeng sebanyak $700 \mathrm{~m} 2$. Pengurus PDA Sumbawa kemudian berupaya semaksimal mungkin agar tanah yang mereka miliki dapat segera dibangun sekolah Taman Kanak kanak 'Aisyiyah Karena di Sumbawa Besar saat itu baru ada sebuah TK ABA yang lokasinya cukup jauh yaitu TK ABA Brang Biji.

Tekad ibu Hj.Sri Sayekti Sugimin bersama ibu Hj.Amanah Chairuddin dan Ibu Hj.Nuryati Multazam dengan cara mengumpulkan dana dari banyak donator kemudian terwujud dengan diadakannya peletakan batu pertama pembangunan TK ABA Panto Daeng bersamaan dengan pembukaan Musyda PDM dan PDA Sumbawa Besar pada tahun 1996. Ibu Sri Sayekti Sugimin menjelaskan bahwa jika kita memiliki tekad yang sangat kuat dan ikhlas maka keinginan 
Insya Allah pasti akan berhasil. Pada tahun pertama setelah pembukaan TK 'Aisyiyah Panto Daeng murid semua berasal dari anak-anak dan cucu para pengurus dan simpatisan 'Aisyiyah di Kabupaten Sumbawa Besar,sehingga fasilitas alatalat permainan juga hasil sumbangan warga Muhammadiyah .

Penyelenggaraan TK ABA Panto Daeng berdasarkan pada visi dan missi TK ABA secara nasional sehingga dalam pelaksanaannya betul betul mengetahui dan memahami hakekat dan tujuan pendidikan Taman Kanak kanak yaitu : terciptanya sistem pendidikan pra sekolah yang kondusif,demokratis,Islami yang diridhoi Allah SWT, dalam rangka mengembangkan potensi anak sejak dini sesuai kemampuan dan tingkat perkembangannya.

Ibu Dra.Hj.Salmah sebagai kepala sekolah yang pertama mengembangkan misi TK ABA di TK ABA Panto Daeng yaitu : (1). Membekali perkembangan anak dengan keimanan sehingga mereka menjadi anak yang beriman dan bertakwa. (2). Mengembangkan potensi anak sedini mungkin. (3). Menciptakan suasana yang kondusif dan demokratis dalam perkembangan dan pertumbuhan anak selanjutnya.

Ibu kepala sekolah pada periode sekarang yaitu Ibu Halimah S.Pd juga berjuang agar tujuan diselenggarakannya pendidikan Taman Kanak Bustanul Athfal dapat terwujud. Adapun tujuan tersebut adalah : (1). Mendidik manusia muslim berakhlak mulia,cakap,percaya diri dan berguna bagi masyarakat, bangsa dan negara. (2). Membantu meletakkan dasar ke arah perkembangan sikap pengetahuan,keterampilan dan daya cipta yang diperlukan oleh anak dalam rangka menyesuaikan diri dengan lingkungannya dan pertumbuhan serta perkembangan selanjutnya (3). Memabantu mengembangkan seluruh potensi dan kemampuan fisik,intelektual,emosional,moral dan agama secara optimal dalam lingkungan pendidikan yang kondusif,demokratis dan kompetetif. (4). Mengembangkan benih-benih keimanan dan ketakwaan kepada Allah SWT sedini mungkin dalam kepribadian anak yang terwujud dalam perkembangan kehidupan jasmaniah dan rohaniah sesuai dengan tingkat perkembangannya.

TK ABA Panto Daeng memiliki 7 (tujuh) orang guru : (1). Kepala Sekolah : Ibu Siti Halimah S.Pd dengan NIP : 19650822198602 2005,Pendidkan terakhir S1 Bimbinagn Konseling. (2). Ibu Rina Ahyar,S.Pd.AUD dengan NIP ; 19840220200801 2009. Pendidikan terakhir UT PG PAUD (3).Ibu Sarifah S.Pd NIP :19700815 2007012026 Jurusan Tekpen UNSA. (4). Ibu Widia Adtuti (5). Ibu
Novillia Hasari S.Pd.AUD (6). Anita Permatasari SE (7). Nurlaila. Tahun Pelajaran 2018/2019 TK ABA Panto Daeng memiliki jumlah siswa sebanyak 68 (enampuluh delapan) anak.

Sejarah Singkat Taman Kanak-kanak 'Aisyiyah Dalam Kecamatan Taliwang Kabupaten Sumbawa Barat semula dibangun pada tahun 2000 oleh PDM Sumbawa Barat sebagai kebutuhan akan adanya Taman Kanak Kanak di kecamatan Taliwang. PDM Sumbawa Barat menjadi PDM setelah berpisah dengan Kabupaten Sumbawa pada tahun 2000 karena adanya pemekaran wilayah. Kecamatan Taliwang Sumbawa berubah menjadi Kabupaten Sumbawa Barat. Demikian juga Pimpinan Cabang Muhammadiyah Taliwang juga berubah menjadi Pimpinan Daerah Demikian juga dengan Pimpinan Daerah 'Aisyiyah Kabupaten Sumbawa Barat,pasca pemekaran wilayah yang semula adalah PCA Taliwang berubah menjadi PDA Kabupaten Sumbawa Barat. Kepengurusan periode pertama dipimpin oleh Ibu Hj.Fatimah Athur BS dan sekretaris Ibu Hj. Icho Nurhayati

Amal usaha yang didirikan pertama kali adalah TK ABA Taliwang dengan nama Taman Kanak-anak 'Aisyiyah Bustanul Athfal dan awal berdiri pada tahun 2005 dan mulai menerima murid pada Tahun Pelajaran 2005 dengan Jumlah Pendidik dan Tenaga Kependidikan 3 Orang dengan Terdiri dari 1 orang PNS, dan 2 orang Non PNS. Pada Tahun 2005/2006 jumlah anak didik mencapai 24 anak didik yang terbagi dalam 2 ruang belajar. TK AISYIYAH BUSTANUL ATHFAL Kecamatan Taliwang Kabupaten Sumbawa Barat maju dan berkembang seiring dengan adanya perubahan kurikulum dari Kemendiknas dengan berbagai macam program-program unggulan. Hasil keputusan bersama seluruh warga sekolah komite, masyarakat dan stacke holder maka TK Aisyiyah Bustanul Athfal berganti nama menjadi TK 'Aisiyah Dalam pada tanggal 09 Nopember 2009.

Pelaksanaan Pembelajaran $\mathrm{Al}$ Islam dan Kemuhammadiyahan di TK ABA Panto Daeng dan TK ABA Taliwang Sumbawa Besar.

1. Dalam bidang aqidah : materi yang ditanamkan adalah meliputi tentang ciptaan Allah,antara lain tentang bagian tubuh manusia,unsur keluarga, orang-orang yang berjasa, hewan, tanaman, sayur mayor,buah-buahan dan bungabunga. Menghafal dua kalimat syahadat dan artinya, menyebutkan nama nama sholat lima waktu,mengenal amaliah pada bulan ramadhan, : tentang makan sahur,berpuasa sesuai kemampuan,berbuka puasa,sholat tarawih dan niat puasa. Tentang sifat-sifat Allah : Siswa diminta menyebutkan beberapa sifat 
Allah : Allah Maha Esa, Allah Maha Pencipta, Allah Maha Kuasa, Allah Maha pengasih dan penyayang, Allah Maha Pelindung, Allah maha penolong, Allah Maha Adil.

2. Dalam bidang ibadah : Materi yang di kembangkan adalah: 1). Pengenalan tata cara berthaharoh/wudhu,sholat,rukun iman,rukun Islam,membaca Al Qur'an. 2). Pengembangan dari materi tentang thaharah di fokuskan pada tatacara wudhu. Siswa ditekankan agar mengikuti tatacara wudhu seperti yang diajarkan dalam Himpunan Putusan Tarjih Muhammadiyah. 3). Materi tentang sholat,anakanak diperkenalkan tentang tata cara solat,nama-nama sholat 5 waktu,menirukan gerakan dan bacaan sholat,keutamaan sholat berjama'ah. 4). Materi tentang bacaan Al Qur'an berupa hafalan surat-surat pendek yang mampu dihafal oleh siswa sesuai tingkatan usianya. 5). Materi tentang haji,yaitu pengenalan tentang tata cara berhaji. Pada umumnya Taman Kanakkanak ABA di TK Panto Daeng dan TK ABA Taliwang mengikuti saran dari Majelis Dikdasmen PP Aisyiyah agar pelaksanaan manasik haji dilaksanakan di sekitar lingkungan sekolah. 7). Materi tentang rukun Islam difokuskan pada pengenalan tentang isi dari rukun Islam. 8). Terkait materi tentang akhlak,pengembangan materi pada bagaimana akhlak kepada orangtua,akhlak kepada Allah,kahlak kepada makhluk Allah yang lain dimuka bumi. 9). Pada materi tentang muamalah yang dikembangkan adalah muamalah terhadap keluarga,teman,guru dan lain-lain. Secara praktis anak dikenalkan bagaimana cara membantu orang lain,menghargai orangtua,mengucapkan salam ketika akan pergi dari rumah dan ketika kembali lagi ke rumah. 10). Kepada guru,siswa dikenalkan bagaimana car menghormati guru dengan mengucapkan dan menjawab salam saat bertemu atau berpisah,mengucapkan terima kasih saat diberi sesuatu. 11). Pada materi tentang do'a dan membaca Al-Qur'an siswa diperkenalkan dan menghafal ayat-ayat pendek secra klasikal dan personal. Misalnya do'a akan makan,do'a menjelang tidur,do'a sebelum belajar dan sesudah belajar. 12). Sementara untuk hafalan surat pendek diantaranya menghafal surat Al Ikhlas,Al Ma'un,Al Ashr,Al Alaq,Al Lahab.

3. Pada materi Keaisyiyahan dan Kemuhammadiyahan pengenalan materi yaitu pada pembelajaran Keaisyiyahan dan Kemuhammadiyahan di TK ABA bertujuan untuk mengenalkan dan meletakkan dasar pengetahuan tentang organisasi KeaisyiyahanKemuhammadiyahan. Kegiatan ini menggunakan pendekatan integrative dengan pengembangan pendidikan agama Islam. Disajikan sebagai satu kesatuan yang bulat dan tidak terpisah. Pengembangan pendidikan Keaisyiyahan/ Kemuhammadiyahan disampaikan dengan bahasa yang sederhana dan menggunakan metode yang menarik melalui cerita, menyanyi/ lagu, gambar atau lambang, wisata, kunjungan, bahasa dan sikap. Tujuan pembelajaran pendidikan Keaisyiyahan dan Kemuhammadiyahan adalah : a)Anak mengenal organisasi 'Aisyiyah/Muhammadiyah, b)Pengenalan pendiri 'Aisyiyah dan Muhammadiyah, c)Pengenalan tujuan organisasi 'Aisyiyah dan Muhammadiyah, d)Pengenalan amal usaha 'Aisyiyah/ Muhammadiyah empat ruang lingkup tersebut di jabarkan dalam materi pembelajaran, e)Pengucapan dan arti kata 'Aisyiyah, f)Pengucapan Taman Kanak-kanak Bustanul Athfal arti dan tujuannya, g)Lagu mars TK 'Aisyiyah Bustanul Athfal, h)Syair lagu mars 'Aisyiyah, i)Pengucapan dan arti kata Muhammadiyah, j)Syair organisasi Muhammadiyah, k)Lagu-lagu Muhammadiyah yang sederhana, l)Pengenalan lambang 'Aisyiyah, Muhammadiyah, Nasyiatul 'Aisyiyah,Pemuda Muhammadiyah, Tapak Suci Putra Muhammadiyah, Ikatan Pelajar Muhammadiyah dan Ikatan Mahasiswa Muhammadiyah, m)Tempat berdirinya Muhammadiyah dan 'Aisyiyah, n)Pengucapan bunyi Q.S Ali Imron ayat 104 dan terjemahnya, o)Tujuan organisasi Muhammadiyah dan 'Aisyiyah, p)Kelanjutan TK 'Aisyiyah yaitu SD,SMP,SMA Muhammadiyah, q)Amal usaha Muhammadiyah dan 'Aisyiyah, r)Pengucapan surat Al-Ma'un.

\section{SIMPULAN DAN SARAN}

Berdasarkan hasil penelitian yang telah dikemukakan maka ada beberapa kesimpulan dan saran sebagai berikut :

1. Perlu adanya pendalaman pada penulisan sejarah Muhammadiyah dan 'Aisyiyah di Sumbawa Besar dan Sumbawa Barat.

2. Dalam pembelajaran $\mathrm{Al}$ Islam dan Kemuhammadiyahan di TK 'Aisyiyah Panto Daeng Sumbawa Besar dan TK Aisyiyah Taliwang Sumbawa Barat ditemukan adanya kesamaan pola pembelajaran. Kesamaan ini dipengaruhi oleh persamaan penguasaan guru 
terhadap materi $\mathrm{Al}$ Islam dan Kemuhammadiyahan.

3. Masih minimnya strategi pembelajaran yang menarik dalam penanaman nilai-nilai Al Islam dan Kemuhammadiyahan sehingga perlu adanya pola dan model strategi pembelajaran AIK bagi anak usia Taman Kanak-kanak.

4. Perlu adanya pelatihan bagi guru terkait pemahaman mendalam terhadap konsep ibadah berdasarkan manhaj Muhammadiyah sehingga dalam pembelajaran AIK acuan utamanya adalah Himpunan Putusan Tarjih Muhammadiyah.

5. Kepada Majelis Dikdasmen PDA Sumbawa Besar dan PDA Kabupaten Sumbawa Barat penelitian ini bisa menjadi masukan untuk pengembangan pembelajaran $\mathrm{Al}$ Islam kemuhammadiyahan di Taman Kanak-Kanak

\section{DAFTAR RUJUKAN}

Fasli, Jalal. (2010) Strategi Peningkatan Mutu Pendidikan Anak Usia Dini,Makalah Dalam Semiloka Nasional Anak Usia Didi Berbasis Keluarga Dalam Membangun Karakter Bangsa, Universiats Negri Yogyakarta.

MB.Miles dan AM Hubermen (2012), Analisis Data Kualitatif,Jakarta: Alfabeth

Mohammad Ali dan Marpuji Ali, (2015) Mazhab Al Ma'un Tafsir Ulang Praksis Pendidikan Muhammadiyah Yogyakarta dan Surakarta : Kerjasama antara Aperon-Philotes dan SD Muhammadiyah Program Khusus Kottabarat.

Moh Fadilah dan Lilif Mualifatu (2013) Pendidikan Karakter Anak Usia Dini,Yogyakarta: Ar Ruzz.

Mulyana (2016),Metode Penelitian Kualitatif,CV Tarsito,Bandung.

Pimpinan Pusat 'Aisyiyah Bagian Dikdasmen (2013)Pengembangan Al Islam Taman Kanak Kanak Bustanul Athfal 'Aisyiyah,Jakarta: Zikrul Hakim.

Mappanyompa, Husnan: (2019) Pengaruh Pendidikan Kemuhammadiyahan Terhadap Sikap Perilaku Siswa, 4 (1) 17-29 (2017) Pengembangan Keaisyiyahan Kemuhammadiyahan Taman Kanak Kanak Bustanul Athfal. Jakarta

Pimpinan Pusat 'Aisyiyah (2012) Pedoman dan Model Pembelajaran PAUD 'Aisyiyah Bustanul Athfal,Jakarta.

Sejarah Pertumbuhan danPerkembangan 'Aisyiyah,Yogyakarta.

(2010) Himpunan Qoi'dah Pedoman dan Peraturan Organisasi 'Aisyiyah, Yogyakarta.
Rof'ah (2016) Posisi dan Jatidiri 'Aisyiyah Perubahan dan Perkembangan: 19171998,Yogyakarta.

Suara 'Aisyiyah,No 3 Maret 2018

Sugiyono. (2012). Penelitian Kuantitatif Kualitatif dan $R \& D$. Bandung: Alfabeta.

Suharsimi Arikunto (2006), Metodologi Penelitian Teori dan Praktek, Bandung: Rineka Cipta. 